\section{Analysis of Electrophoresis Isozyme Patterns Using a Microcomputer- based Imaging System}

\author{
A.R. Dixon ${ }^{1}$, R.B. Boone ${ }^{2}$, A. Gardea ${ }^{3}$, L.S. Daley ${ }^{4}$, and T.L. \\ Righetti $^{4}$ \\ Department of Horticulture, Oregon State University, Corvallis, OR \\ 97331.
}

Additional index words. acid phosphatase, Corylus, filbert, hazel, peroxidase, phenol oxidase, plant fingerprinting, polyacrylamide

\begin{abstract}
A microcomputer-based image processing system was used to simplify the large number of visual comparisons required to identify various Corylus spp., cultivars, and clonal accessions using polyacrylamide gel electrophoresis isozyme patterns. Photographs of gels stained for peroxidase, acid phosphatase, and phenol oxidase were digitally captured and selected lanes were enhanced and scanned. The scan data were analyzed to locate bands and normalize their position to that of standards. Such data were plotted and a computer-generated isozyme pattern was displayed. Compressed image data were then stored in a database for subsequent automated isozyme pattern comparisons. Photographic records that were previously used in published reports were reevaluated with the computerized system. Species, cultivars, or clones that were characterized in visual evaluations were similarly characterized using the computer method. Computer evaluations usually identified more bands. Band positions were only rarely different and probably resulted from better normalization relative to standard bands when using the computerized procedure.
\end{abstract}

The National Clonal Germplasm Repository (NCGR). system collects, maintains, identifies, and characterizes clones of selected crop genera. As collections grow, identification and classification of new entries become more complex. For example, some genera maintained at the NCGR in Corvallis, Ore., already have close to 2,000 accessions (Jahn and Westwood, 1982). Thus, there is clearly a need for exact clonal identification procedures that can efficiently classify germplasm.

Biochemical identification of plant species and cultivars has received increased attention from plant breeders, the nursery industry, growers, and U.S. trade officials (Santamour and Demuth, 1980; Wolfe, 1976). In our work for NCGR, isozyme patterns of stem extracts of various species were resolved in all seasons (Ahmed et al., 1987; Menendez and Daley, 1986), and the patterns were constant for each clone (Ahmed et al., 1987; Menendez and Daley, 1986; Menendez et

Received for publication 22 May 1989. Contribution of Oregon State Agricultural Experiment Station in cooperation with ARS/USDA, and published as Oregon Agricultural Experiment Station Technical Paper no. 9255. We thank the Horticultural Research Institute for equipment funding and the U.S. Dept. of Agriculture, Agricultural Research Service, under specific Cooperative Agreement no. .58-0401 -7-00154. The cost of publishing this paper was defrayed in part by the payment of page charges. Under postal regulations, this paper therefore must be hereby marked advertisement solely to indicate this fact.

'Senior Research Assistant.

${ }^{2}$ Research Assistant.

${ }^{3}$ Graduate Student.

${ }^{4}$ Associate Professor. al., 1986) regardless of plant age (Menendez. and Daley, 1986). Experienced personnel can visually compare photographic records (PR) of isozyme patterns obtained by electrophoresis and consistently identify various clones. However, differences are often subtle, and considerable skill and experience are required. It is highly desirable that these comparisons be conducted by more objective means. Another limitation of visual inspection is the need to constantly compare the PR of specific accessions against all available PRs. Such comparisons with many accessions are difficult, especially when up to four isozyme patterns maybe required for identification.

The recent availability of relatively lowcost image capture and processing hardware for microcomputers permits the design and implementation of a system for enhancing, zyme patterns. Condensed output can be placed in database software for sorting, classification, and identification of isozyme patterns by individuals without sophisticated electrophoretic interpretation skills. This paper describes the utility of such a system.

Plant material was obtained from the NCGR, Corvallis, Corylus collection. Protein extraction was conducted as described by Menendez and Daley (1986). One-yearold shoots (except when otherwise indicated) were stored at $-30 \mathrm{C}$ before extraction since such storage is known to induce polyphenol oxidase (EC 1.10.3.2) activity (Daley et al., 1987). Electrophoresis was performed as previously described (Menendez and Daley, 1986) except that the room was at 3C. Staining for peroxidase (EC 1.11.1.7) and acid phosphatase (EC 3.1.3.2) was conducted as condensing, classifying, and identifying iso- described by Shaw and Prasad (1970) and phenol oxidase (EC 1.14.18.1) following Hare (1970). Enzyme substrates were: beta-naphthyl acid phosphate for acid phosphatase; 3amino-9-ethyl carbazole for peroxidase; and catechol:p-phenylenediamine for phenol oxidase. A poorly defined region in the cathodic, low-density part of the gel stained lightly with all stains. This problem was attributed to the formation of enzyme polymers during extraction and was not useful for identification.

Gels were photographed with positivenegative film (Type 55, Polaroid, Cambridge, Mass.). These photographs were digitized and stored on a disk using a microcomputer-based image processing system. A JVC CCD TK-870U video camera with JVC HZ-C611AF(U) lens (JVC Co. of America, Elmwood Park, N. J.) was used to scan the photograph negatives. The video camera output was input to an AT\&T Truevision (TARGA-24) image capture, digitizing, and display adapter with $512 \times 512$ pixel resolution and 256 levels of intensity for each of the red, green, and blue pixel components (AT\&T Electronic Photography and Imaging Center, Indianapolis, Ind.). This adapter was installed in an IBM-AT microcomputer with 100 megabytes of fixed disk storage and 1.5 megabytes -of random access memory. Gel images were recalled from disk and the inverse of pixel intensity (to produce a positive image) was displayed on a high resolution color monitor (SONY Trinitron CPD-1201, SONY Corp., Fujisawa, Japan). The software was written in $\mathrm{C}$ (Microsoft C, Version 5.1, Microsoft Corp., Redmond, Wash.) in menu-driven modular form.

Lanes to be scanned in the displayed stained gel images were interactively defined using a mouse to specify screen coordinates. The lane(s) of interest were then enhanced using a linear contrast stretch (Fig. 1). Digital filtering across the lanes (Elder and Southern, 1987a) was used to reduce noise in the scan. Scan data were collected across the selected lanes of the enhanced gel image and then smoothed using a simplified least-squares procedure (Savitzky and Golay, 1964) (Fig. 1). The scan data consist of average pixel intensity level (O to 255) for the selected lanes at $\approx 500$ intervals along the length of a lane, and were stored on disk for subsequent analysis. These results were normalized to the standard for each gel and to the standard for the series. The peaks in the scan data were found by applying a peak-finding routine using the first and second derivatives of the scan data similar to the method described by Elder and Southern (1987b). The isozyme pattern was then reconstructed from the normalized scan data, displaying located bands (Fig. 1, bottom). In this example, all bands were assigned the same intensity, and widths were defined as one-half the distance between the beginning and midpoints plus onehalf the distance between mid- and end points of the peaks. Other criteria, such as midpoint plus and minus some constant, could work equally well. The sensitivity of this routine can be interactively adjusted. Increasing sen- 

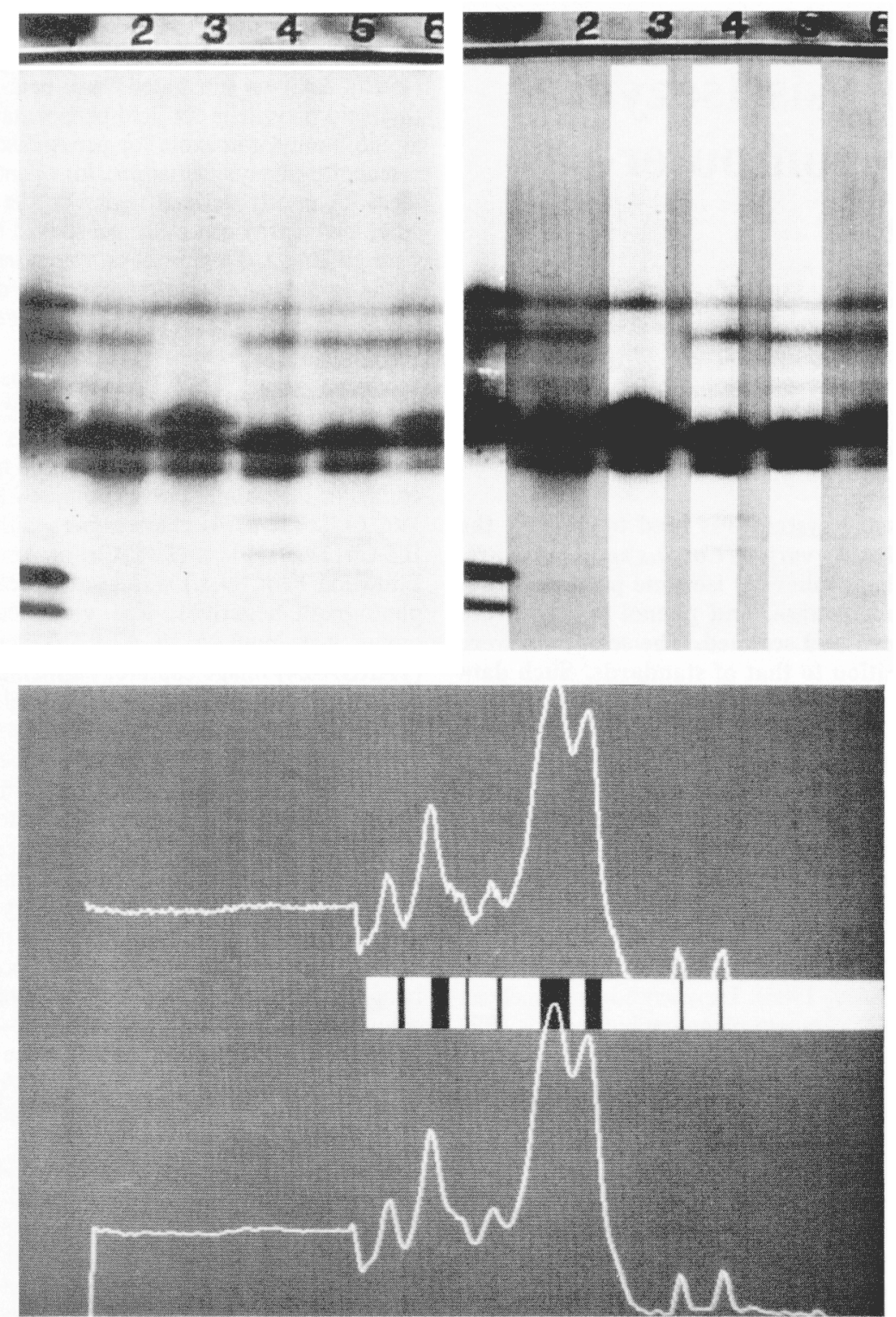

Fig. 1. Electrophoretic gel enhancement using the computer gel analysis system. The phenol oxidase isozyme pattern from a filbert (Corylus) stem is shown. (top) Comparison of original isozyme pattern (left) and enhanced pattern (right). (bottom) Reconstructed gel pattern for lane 5 with scan of enhanced pattern displayed above and smoothed scan displayed below.

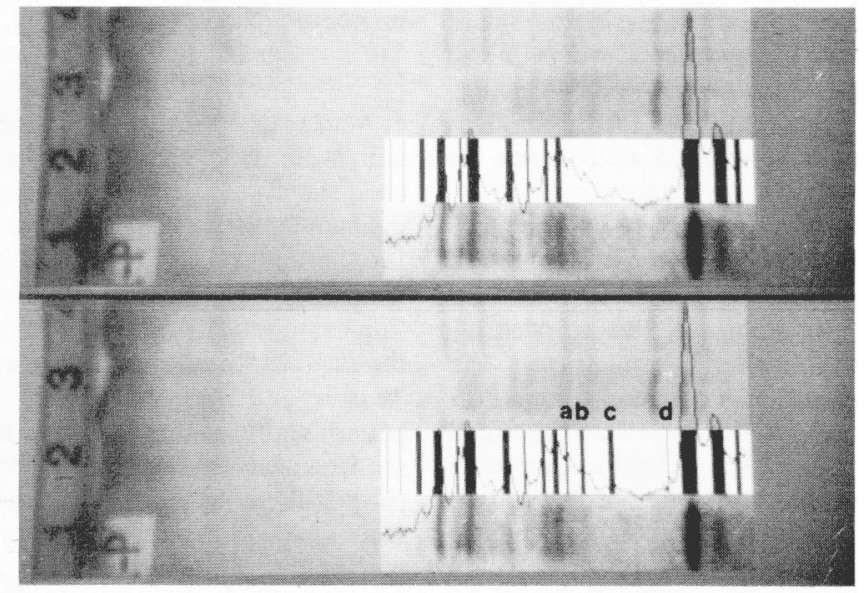

Fig. 2. Images of peroxidase isozyme patterns fromCorylus spp. (top) Lane one was enhanced and scanned. The resulting computer-regenerated isozyme pattern is shown superimposed over lane 2 and the scan is plotted over the image. Lanes 3 and 4 are other Corylus spp. and are not enhanced. (bottom) The same gel processed as above, except with increased peak-finding sensitivity. Additional bands detected include: $(\mathrm{a}, \mathrm{b})$ visible in the enhanced lane $1 ;$ (c) visible as a peak in the plotted scan; and (d) probably spurious. sitivity usually revealed bands that were difficult to resolve, but also usually recorded spurious peaks in the scan data. In the analysis shown in Fig. 2, four additional bands were recorded, two of which can be seen in the enhanced gel image, one of which can be seen as a peak in the scan plot, and one of which is probably spurious. In cases of bands that are particularly difficult to resolve, a more interactive peak-finding routine was used. The scan data were displayed over the enhanced gel image and a mouse was used to locate each peak (Fig. 3). In either case, the band locations given as beginning, mid- and end points of peaks in the scan data as well as relative densities were stored on disk.

Normalized, condensed gel data can be read into commercially available database software. In our application, dBase III+ (Ashton-Tate Torrance, Calif.) was used with a database structure and program that allows sorting and comparisons of up to 25 band positions that can be evaluated for both presence and intensity. Isozyme patterns obtained from plants of an unknown source can be matched-with known patterns from an isozyme pattern database with minimal effort. Near matches, common bands, and other quantifiable similarities and differences can also be obtained.

For more rigorous interpretation of gel patterns, additional analysis of derivatives of scan data ean be used to find peaks with illdefined summits. This additional information can be added to the database.

To test the utility of the system, the acid phosphatase, peroxidase, and phenol oxidase isozyme patterns from 26 arbitrarily selected filbert (Corylus) species, cultivars, or clonal accessions were processed and stored in a database. Similar banding patterns were assigned to categories and these groupings were compared to published patterns (Ahmed et al., 1987) for the same species, cultivars, and clones. Each computer-derived pattern was used to select the closest match (highest number of similar bands) among the published patterns for each isozyme. Six independently obtained high quality patterns for C. avellana 'Barcelona' were also added to the database. When the computer-derived pattern from any one of these gels was used as the search pattern, all other occurrences of 'Barcelona' in the database were selected as matches.

In Table 1 we compare the number of bands found by the computer method with those found by Ahmed et al. (1987). The computer procedure identified more bands in $86 \%$ of the cases. (Not all bands were considered in the visual method.) When using the computer-assisted method, it is less cumbersome to consider a larger number of bands than in visual evaluations. Bands that were identified visually were almost always identified with the computer procedure. Fewer or different bands were only rarely identified.

A comparison of the patterns found by the computer method with those found by Ahmed et al. (1987) is displayed in Table 2. Each unique pattern was assigned to a different group. The left three columns in Table 2 for 
Table 1. Differences in number of bands published previously and located by the computer method.

\begin{tabular}{|c|c|c|c|c|c|c|c|c|c|c|c|c|c|}
\hline \multirow{2}{*}{$\begin{array}{l}\text { Species, cultivar, or } \\
\text { clonal accession } \\
\text { (NCGR number) }\end{array}$} & & \multicolumn{4}{|c|}{ No. published bands ${ }^{2}$} & \multicolumn{4}{|c|}{ No. computer-found bands ${ }^{2}$} & \multicolumn{4}{|c|}{ Different $^{z}(\%)$} \\
\hline & & $\mathrm{AP}$ & $\mathrm{P}$ & $\mathrm{PPO}$ & Total & $\mathrm{AP}$ & $\mathrm{P}$ & PPO & Total & AP & $\mathrm{P}$ & $\mathrm{PPO}$ & Total \\
\hline \multicolumn{14}{|l|}{ Corylus avellana } \\
\hline Barcelona (36) & & 7 & 6 & 4 & 17 & 8 & 10 & 6 & 24 & 114 & 167 & 150 & 141 \\
\hline C. avellana Brixnut (26) & & 6 & 4 & 5 & 15 & 7 & ...y & 8 & $\cdots$ & 117 & --- & 160 & --- \\
\hline C. avellana Casina (28) & & 6 & 5 & 5 & 16 & 7 & 9 & $-\cdots$ & -- & 117 & 180 & $\cdots$ &.-- \\
\hline \multicolumn{14}{|l|}{ C. avellana Crossal de } \\
\hline Constanti (75) & & 6 & 4 & 5 & 15 & 7 & -- & 10 & --- & 117 & $\cdots$ & 200 & $\cdots$ \\
\hline C. avellana Fitzgerald (27) & & 7 & 2 & 2 & 11 & 8 & 8 & -- & $\cdots$ & 114 & 400 & $\cdots$ & --- \\
\hline \multicolumn{14}{|l|}{ C. avellana var. } \\
\hline fuscorubra (39) & & 8 & 6 & 5 & 19 & 8 & 12 & 8 & 28 & 100 & 200 & 160 & 147 \\
\hline C. avellana-Gem (23) & & 6 & 5 & 6 & 17 & 8 & 12 & 10 & 30 & 133 & 240 & 167 & 176 \\
\hline C. avellana Gironenc (44) & & 7 & 5 & 6 & 18 & 6 & 9 & 10 & 25 & 86 & 180 & 167 & 139 \\
\hline C. avellana Italian Red (30) & 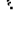 & 6 & 5 & 6 & 17 & 6 & 13 & 10 & 29 & 100 & 260 & 167 & 171 \\
\hline C. avellana Kruse (25) & & 7 & 2 & 1 & 10 & 7 & 9 & 4 & 20 & 100 & 450 & 400 & 200 \\
\hline \multicolumn{14}{|l|}{ C. avellana var. } \\
\hline heterophylla (159) & & 7 & 3 & 4 & 14 & 8 & 10 & $\cdots$ & $m$ & 114 & 333 & --- & --- \\
\hline C. avellana Montebello (17) & & 7 & 5 & 5 & 17 & 8 & 12 & 9 & 29 & 114 & 240 & 180 & 171 \\
\hline C. avellana Mortarella (51) & & 7 & 6 & 6 & 19 & 8 & 13 & $\cdots$ & -- & 114 & 217 & --- & -- \\
\hline C. avellana Negret (8) & & 7 & 4 & 4 & 15 & 8 & 11 & -- & --- & 114 & 275 & --- & $\cdots$ \\
\hline C. avellana Neue Riesennuss (10) & & 6 & 6 & 6 & 18 & 7 & --- & 6 & --- & 117 & $\cdots$ & 100 & --- \\
\hline C. avellana OSU $14-84$ (52) & & 7 & 4 & 2 & 13 & 8 & 10 & -- & -- & 114 & 250 & $\cdots$ & $\cdots$ \\
\hline C. avellana OSU 54-50 (93) & & 6 & 5 & 3 & 14 & 7 & 13 & 8 & 28 & 117 & 260 & 267 & 200 \\
\hline C. avellana Segorbe (20) & & 7 & 5 & 6 & 18 & 8 & 13 & 11 & 32 & 114 & 260 & 183 & 178 \\
\hline C. avellana Tombul Ghiaghli (55) & & 7 & 6 & 6 & 19 & 6 & 10 & --- & -- & -86 & 167 & $-\infty$ & $\cdots$ \\
\hline C. avellana Tonda Bianca (21) & & 7 & 5. & 5 & 17 & 9 & 12 & --- & --- & 129 & 240 & $\cdots$ & $\cdots$ \\
\hline C. avellana Woodford (12) & & 6 & 4 & 2 & 12 & 7 & 11 & --- & $\cdots$ & 117 & 275 & -- & --- \\
\hline C. columa var. chinensis (19) & & 7 & 3. & 3 & 13 & 8 & 10 & $\cdots$ & $\cdots$ & 114 & 333 & --- & --- \\
\hline C. heterophylla (18) & & 7 & 3 & 4 & 14 & 7 & 10 & 7 & 24 & $\therefore 100$ & 333 & 175 & 171 \\
\hline C. sp. BR-4-1 (136) & & 6 & 4 & 4 & 14 & 7 & --- & 10 & -- & 117 & --- & 250 & --- \\
\hline C. sp. USOR 5-70 (125) & & 7 & 3 & 4 & 14 & 8 & 9 & 9 & 26 & 114 & 300 & 225 & 186 \\
\hline C. sp. USOR 6-73 (144) & & 7 & 5 & 4 & 16 & 7 & 9 & 10 & 26 & 100 & 180 & 250 & 163 \\
\hline Mean & & & - & & & & & & & 111 & 261 & 200 & 170 \\
\hline
\end{tabular}

${ }^{7} \mathrm{AP}$, acid phosphatase; $\mathrm{P}$, peroxidase; $\mathrm{PPO}$, phenol oxidase.

${ }^{y}---=$ gel for this species, cultivar, or clone not available.

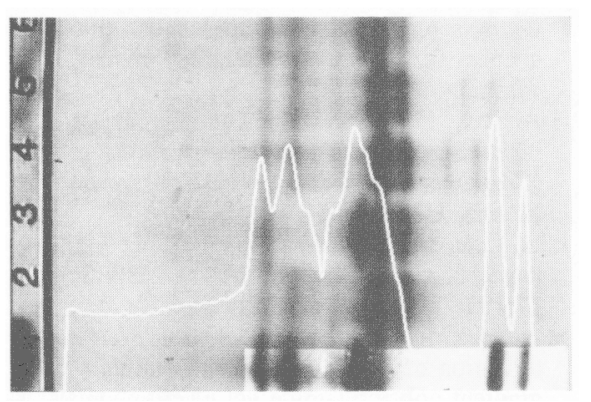

Fig. 3. A screen illustrating the interactive method of peak location. With the scan displayed on the enhanced gel image, itbecomes an easy task to locate peaks using a mouse-controlled cursor.
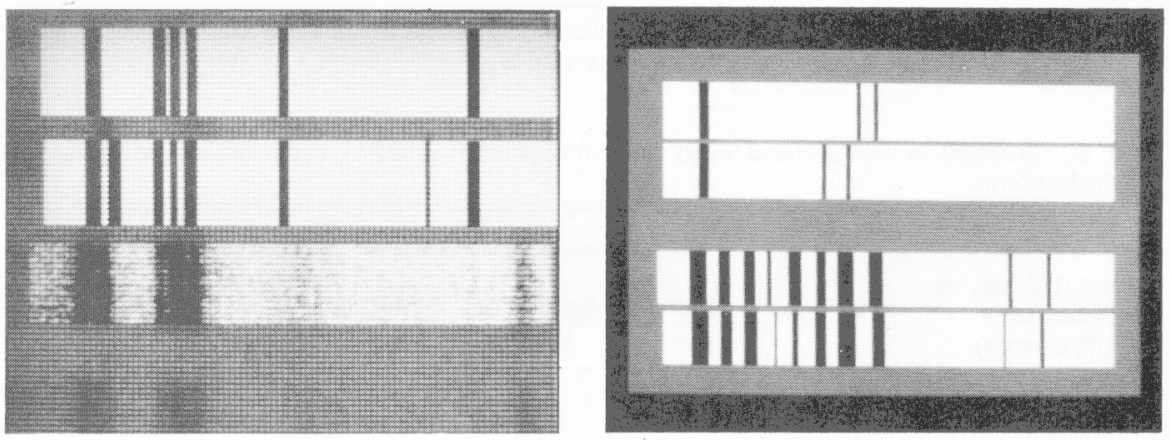

Fig. 4. Illustration of cases where the computer gel analysis system found a pattern different from published patterns. (left) From top to bottom, the published pattern, the computer-normalized, regenerated pattern, the enhanced image, and the original acid phosphatase image for $C$. avellana Gem (23). (right) Published (top two patterns) and computer-regenerated (bottom two patterns) peroxidase patterns from species $C$. heterophylla (18) and C. avellana var. heterophylla (159) whose patterns differ in the previous reports but are remarkably similar after computer evaluation.

vious publication were found in the appropriate position when using the computer procedure. In $80 \%$ of the cases, patterns designated in the Ahmed et al. (1987) paper were the closest match. In the remaining $20 \%$, better matches were found. Half of these better matches are accounted for by using bands not observed by the original researchers.

Table 3 lists the accessions where patterns differed from those published (Ahmed et al., 1987) and the reasons they differed. Most differences occurred in the acid phosphatase patterns and were mainly due to the computer method detecting more bands. There were three instances in which fewer bands were detected and three instancess of bands located in different positions. In cases where position was altered, differences in standardization are a probable cause. Figure 4 (left) illustrates additional band detection for the case of $C$. avellana Gem. The computer-assisted analysis was able to resolve the two bands on the left that were recorded as a single band in the visual method. It also detected the second band from the right, which was not detected in the visual method. Figure 4 (right) reveals differences in both band number and location. Since all 10 bands of the regenerated patterns match, it is likely that position differences reported in the visual three-peak categorization are due to standardization error and the two species should 
Table 2. A comparison of published (Ahmed et al., 1987) and computer-generated isozyme banding patterns for acid phosphatase (AP), peroxidase (P), and phenol oxidase (PPO) found in 26 Corylus Spp., cultivars, and clonal accessions.

\begin{tabular}{|c|c|c|c|c|c|c|c|c|c|}
\hline \multirow{3}{*}{$\begin{array}{l}\text { Species, cultivar, or } \\
\text { clonal accession } \\
\text { (NCGR number) }\end{array}$} & \multicolumn{9}{|c|}{ Enzyme staining pattern } \\
\hline & \multicolumn{4}{|c|}{$\begin{array}{l}\text { Pattern categories } \\
\text { assigned for } \\
\text { computer method } \\
\end{array}$} & \multicolumn{5}{|c|}{$\begin{array}{l}\text { Best-matched pattern } \\
\text { numbers from } \\
\text { published work }\end{array}$} \\
\hline & AP & & $\mathrm{P}$ & PPO & & $\mathrm{AP}$ & $\mathrm{P}$ & & PPO \\
\hline \multicolumn{10}{|l|}{ Corylus avellana } \\
\hline Barcelona (36) & A & & A & A & & 1 & 1 & & 1 \\
\hline C. avellana Montebello (17) & $A$ & & $\mathrm{~B}$ & $\mathrm{~B}$ & & $i_{21}$ & 42 & & 39 \\
\hline C. avellana Mortarella (51) & $\ddot{A}$ & & $\mathrm{C}$ & $\ldots y$ & & 1 & 26 & & -... \\
\hline C. avellana Negret (8) & A & & $\mathrm{D}$ & $\ldots$ & & 1 & 22 & & ... \\
\hline C. avellana OSU 14-84 (52) & A & & $\mathrm{E}$ & --- & & 1 & 25 & & ... \\
\hline C. avellana $\mathrm{Gem}(23)$ & $\mathrm{A}$ & & $\vec{F}$ & $\mathrm{C}$ & & $1_{21}$ & $43^{\circ}$ & & 40 \\
\hline C. avellana Segorbe (20) & A & & $\mathrm{G}$ & $\mathrm{D}$ & & $1_{21}$ & 40 & & 37 \\
\hline \multicolumn{10}{|l|}{ C. avellana var. } \\
\hline heterophylia (159) & B & & $\mathrm{H}$ & -.- & & 4 & 30 & & ..- \\
\hline C. sp. USOR 5-70 (125) & $\mathrm{B}$ & & I & $\mathrm{E}$ & & 4 & 4 & & 4 \\
\hline C. colurna var. chinensis (19) & J & & J & -- & & 4 & 23 & & $\cdots$ \\
\hline C. heterophylla (18) & $\mathrm{C}$ & & $\mathrm{H}$ & $\mathbf{F}$ & & 5 & $30_{5}$ & & 64 \\
\hline C. sp. BR-4-1 (136) & $\mathrm{C}$ & & ... & $\mathrm{G}$ & & 5, & -.- & & 18 \\
\hline C. sp. USOR 6-73 (144) & $\mathrm{C}$ & & $\mathrm{K}$ & $\mathrm{H}$ & & $5^{14}$ & 96 & & 8 \\
\hline C. avellana Woodford (12) & $\mathrm{D}$ & & $\mathrm{L}$ & ... & & 2 & $21_{25}$ & & -.. \\
\hline C. avellana Casina (28) & $\mathrm{D}$ & & $\mathrm{M}$ & -- & & 2 & 24 & & -.. \\
\hline C. avellana Tombul Ghiaghli (55) & $\mathrm{E}$ & & $\mathrm{N}$ & ... & & $25_{20}$ & 826 & & ... \\
\hline C. avellana Italian Red (30) & $\mathrm{E}$ & & 0 & I & & 25 & $45^{26}$ & & 44 \\
\hline C. avellana Brixnut (26) & $\mathrm{F}$ & & $\ldots$ & j & & 14 & --. & & 15 \\
\hline \multicolumn{10}{|l|}{ C. avellana Crossal de } \\
\hline Constanti (75) & $\mathrm{F}$ & & ... & $\mathrm{K}$ & & 14 & .-. & & 14 \\
\hline C. avellana Fitzgerald (27) & G & & $\mathrm{P}$ & - & & $31_{1}$ & 29 & & $-\cdots$ \\
\hline \multicolumn{10}{|l|}{ C. avellana var. } \\
\hline fuscorubra (39) & $\mathrm{H}$ & & $Q$ & $\mathbf{L}$ & & 27 & 47 & & 46 \\
\hline C. avellana Neue Riesennuss (10) & $\mathrm{I}$ & & $\ldots$ & $\mathrm{M}$ & & 13 & -.- & & 13 \\
\hline C. avellana Tonda Bianca (21) & $-\mathbf{J}$ & & $\mathrm{R}^{*}$ & $\ldots$ & & 19 & 28 & & $\ldots$ \\
\hline C. avellana Kruse (25) & $\mathrm{K}$ & & $\ddot{S}$ & $\mathbf{N}$ & & 26 & 32 & & 45 \\
\hline C. avellana Gironenc (44) & $\mathrm{L}$ & & $\mathrm{T}$ & 0 & & 6 & 6 & & 5 \\
\hline C. avellana OSU 54-50 (93) & $\vec{M}$ & & $\bar{U}$ & $\mathbf{P}$ & & $18_{2}$ & 2 & & 2 \\
\hline \multicolumn{10}{|c|}{$\begin{array}{l}\text { Thescript numbers are the published pattern number where disagreement occurred. } \\
\text { Subscies, or clone not available. }\end{array}$} \\
\hline \multicolumn{10}{|c|}{$\begin{array}{l}\text { Table 3. Instances of disagreement when comparing patterns found by computer analysis with pul } \\
\text { lished patterns. }\end{array}$} \\
\hline \multirow{3}{*}{$\begin{array}{l}\text { Species, cultivar, or } \\
\text { clonal accession } \\
\text { (NCGR number) }\end{array}$} & \multicolumn{9}{|c|}{$\operatorname{Band}(\mathrm{s})^{2}$} \\
\hline & \multicolumn{3}{|c|}{ Additional found } & \multicolumn{3}{|c|}{ Fewer found } & \multicolumn{3}{|c|}{$\begin{array}{l}\text { In different } \\
\text { position }\end{array}$} \\
\hline & $\overline{\mathrm{AP}}$ & $\mathrm{P}$ & PPO & $\mathrm{AP}$ & $\mathrm{P}$ & PPO & $\mathrm{AP}$ & $\mathrm{P}$ & $\overline{\mathrm{PPO}}$ \\
\hline C. avellana Fitzgerald (27) & $\mathrm{X}$ & & & & & & & & \\
\hline C. avellana $\mathrm{Gem}(23)$ & $\mathrm{x}$ & & & & & & & & \\
\hline C. avellana Montebello (17) & $\mathrm{X}$ & & & & & & & & \\
\hline C. avellana OSU 54-50 (93) & $\mathrm{X}$ & & & & & & & & \\
\hline C. avellana Segorbe (20) & $\mathrm{X}$ & & & & & & & & \\
\hline C. avellana Tombul Ghiaghli (55) & & & & $\mathrm{X}$ & $\mathrm{X}$ & & & & \\
\hline C. avellana Tonda Bianca (21) & $\mathrm{X}$ & & & & & & & & \\
\hline C. avellana Woodford (12) & & $\mathrm{X}$ & & & & & & & \\
\hline C. heterophylla (18) & & & & & & $X$ & & $\mathrm{X}$ & \\
\hline C. sp. BR-4-1 (136) & & & & & & & $\mathrm{X}$ & & \\
\hline C. sp. USOR 6-73 (144) & & & & & & & & $\mathrm{X}$ & \\
\hline
\end{tabular}

${ }^{7} \mathrm{AP}$, acid phosphatase; $\mathrm{P}$, peroxidase; PPO, phenol oxidase. be in similar categories for this enzyme.

The method of gel analysis described in this paper appears to be a cost-effective, accurate, and time-saving tool for the analysis of gels from polyacrylamide electrophoresis, the determination of isozyme patterns, and the comparison of these patterns. In our comparison with previously published isozyme patterns for a set of Corylus spp. and cultivars, the computer method was successfully used to characterize the species and cultivars. When compared with the visual method, persons unskilled in interpreting gel patterns can perform the characterization task with equal or better effectiveness. Similar results can be obtained regardless of the evaluator, thus biases in interpretation are reduced.

\section{Literature Cited}

Ahmed, Z., L.S. Daley, R.A. Menendez, and H.B Lagerstedt. 1987. Characterization of filbert (Corylus) species and cultivars using gradient polyacrylamide gel electrophoresia. J. Env. Hort. 5:11-16.

Daley, L.S., J.M. Montano, R.A. Menendez, A.H. Soeldner, and R.B. Boone. 1987. Spectroscopic evaluation of freeze damage in pear trees using fourth-derivative visible spectroscopy of bark sections. Spectroscopy 2(9):32-36.

Elder, J.K. and E.M. Southern. 1987a. Computer-aided analyais of one-dimensional restriction fragment gels, p. 165-172. In: M.J. Bishop and C.J. Rawlins (eds.). Nucleic acid and protein sequence analysis: A practical approach. IRL, Washington D.C.

Elder, J.K. and E.M. Southern. 1987b. Automatic reading of DNA sequencing gel autoradiographs, p. 219-229. In: M.J. Bishop and C.J. Rawlins (eds.). Nucleic acid and protein sequence analysis: A practical approach. IRL, Washington D.C.

Hare, R.C. 1970. Physiology and biochemistry of pine resistance to the fusiform rust fungus (Cronartium fusiforme). $\mathrm{PhD}$ Diss., Univ. of Florida, Gainesville.

Jahn, O.L. and M.N. Westwood. 1982. Maintenance of clonal plant germplasm. HortScience 17:122.

Menendez, R.A. and L.S. Daley. 1986. Characterization of Pyrus species and cultivars using gradient polyacrylamide gel electrophoresis. J. Env. Hort. 4:56-60.

Menendez, R. A., F.E. Larsen, and R. Fritts, Jr. 1986. Fingerprinting of apple cultivars by electrophoretic isozyme banding patterns. J. Env. Hort. 4:101-107.

Santamour, F. S., Jr. and P. Demuth. 1980. Identification of Callery pear cultivars by peroxidase isozyme patterns. J. Her. 71:447449.

Savitzky, A. and M.J.E. Golay. 1964. Smoothing and differentiation of data by simplified least squares procedures. Anal. Chem. 36:1627-1638.

Shaw, C.R. and R. Prasad. 1970. Starch gel electrophoresis of enzymes-a compilation of recipes. Biochem. Genet. 4:297-320.

Wolfe, W.H. 1976. Identification of grape varieties by isozyme banding patterns. Amer. J. Enol. Viticult. 2:68-73. 